Supporting information for

\title{
Efficient Coupling of Reaction Pathways of Criegee Intermediates and Free Radicals in the Heterogeneous Ozonolysis of Alkenes
}

\author{
Meirong Zeng and Kevin R. Wilson*
}

Chemical Sciences Division, Lawrence Berkeley National Laboratory, Berkeley, CA 94720, USA.

Corresponding Author*: Kevin R. Wilson (email: krwilson@lbl.gov)

\section{Contents:}

S1. Supporting information for experiments

S1.1. Experimental setup

S1.2. Reaction scheme and product identification

$\mathrm{S} 1.3$. Relative humidity dependence for $\mathrm{Tri}+\mathrm{O}_{3}$ reactions

\section{S2. Supporting information for simulations}

S2.1. Simulation methods and model development

S2.2. Additional mechanistic tests of the model

S2.3. Simulation results for Tri $+\mathrm{OH}$ reactions in the CFSTR

$\mathrm{S} 2.4$. Simulation results for $\mathrm{Tri}+\mathrm{O}_{3}$ reactions in the flow reactor 


\section{S1. Supporting information for experiments}

\section{S1.1. Experimental setup}

The experimental setup consists of three main parts: (1) plumbing and instrumentation that feeds gas and particles to the (2) reactor and (3) particle and mass spectrometry detectors used to quantify heterogeneous kinetics. Detailed descriptions can be found in prior references so only a brief overview will be provided here. ${ }^{1-3}$

Polydisperse liquid aerosols are produced by passing dry $\mathrm{N}_{2}$ through a heated Pyrex tube, located in a temperature-controlled furnace. The Pyrex tube is filled with liquid cis-9-tricosene (Tri, Sigma-Aldrich, 97\% pure) or mixed with 2-octyl-1-dodecanol (Sigma-Aldrich, 97\% pure). The furnace temperatures are adjusted for each experiment to generate stable droplets $\left(\sim 110^{\circ} \mathrm{C}\right.$ for pure Tri aerosols and several degrees lower for the Tri/2-octyl-1-dodecanol mixtures). Residual gas-phase organics are removed prior to the reactor by passing the aerosols $/ \mathrm{N}_{2}$ flow through an annular activated charcoal denuder. The aerosol flow is then mixed with gas flows that include the oxidants (i.e. $\mathrm{H}_{2} \mathrm{O}_{2}$ or $\mathrm{O}_{3}$ ), $\mathrm{O}_{2}$ and humidified (or dry) $\mathrm{N}_{2}$.

For ozonolysis, the mixture of aerosols and gases $\left(\mathrm{O}_{3}, \mathrm{O}_{2}\right.$, humidified or dry $\left.\mathrm{N}_{2}\right)$ are introduced into a flow reactor (Fig. S1) with an average residence time of $\sim 37$ seconds at a total flow of 1.1 SLM. $\mathrm{O}_{3}$ is produced by passing $0.05-\mathrm{SLM} \mathrm{O}_{2}$ through a corona discharge generator, which is diluted by dry $\mathrm{N}_{2}(3 \mathrm{SLM})$. The $\mathrm{O}_{3}$ concentration $(0-10 \mathrm{ppm})$ is then measured with an ozone monitor (2B technology model 202M). 


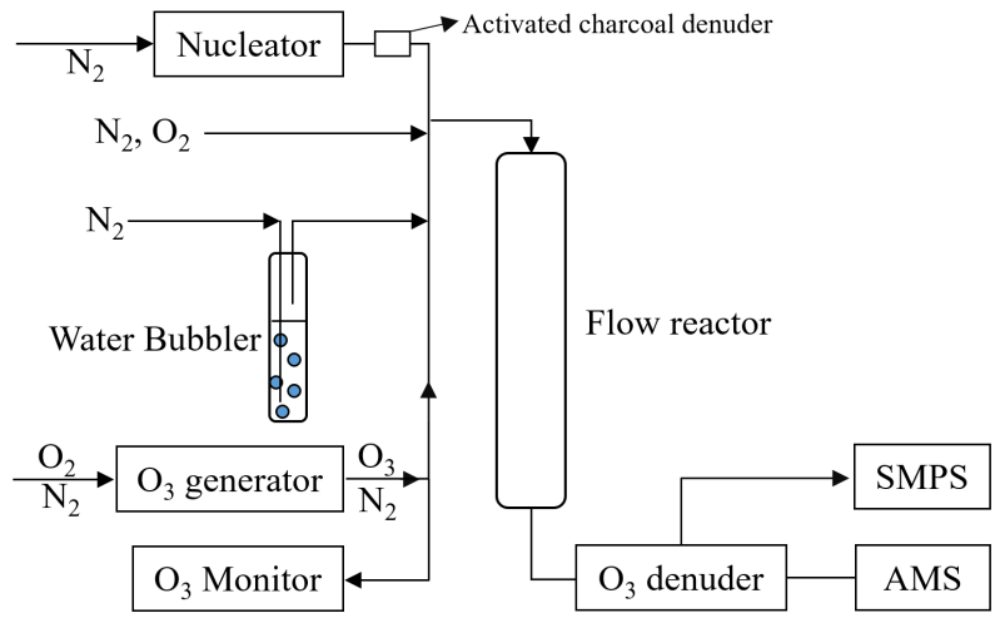

Figure S1. A schematic view of the flow reactor used in the heterogeneous ozonolysis experiments. The SMPS and AMS are scanning mobility particle sizer and aerosol mass spectrometer, respectively.

For the $\mathrm{OH}$ oxidation experiments, the mixture of aerosols and gases $\left(\mathrm{H}_{2} \mathrm{O}_{2}, \mathrm{O}_{2}\right.$, humidified or dry $\mathrm{N}_{2}, \mathrm{OH}$ tracer) are introduced into a continuous flow stirred tank reactor (CFSTR) as shown in Fig. S2. OH is generated in situ by the photolysis of gas-phase $\mathrm{H}_{2} \mathrm{O}_{2}(<10$ ppm) using UV lamps $(\lambda \sim 356 \mathrm{~nm}) . \mathrm{H}_{2} \mathrm{O}_{2}$ vapor is generated by passing the dry $\mathrm{N}_{2}(0.1 \mathrm{SLM})$ through a heated bubbler $\left(60{ }^{\circ} \mathrm{C}\right)$ containing a 50/50 mixture urea-hydroperoxide $\left(\mathrm{CO}\left[\mathrm{NH}_{2}\right]_{2} \cdot \mathrm{H}_{2} \mathrm{O}_{2}\right.$, Sigma-Aldrich, $97 \%$ pure) and sand $\left(\mathrm{SiO}_{2}, 50-70\right.$ mesh particle size, Sigma-Aldrich). The concentration of gas-phase $\mathrm{H}_{2} \mathrm{O}_{2}$ in the CFSTR after $\sim 2$ hours of filling is several ppm $(<10 \mathrm{ppm})$, which is measured by a Vaisala $\mathrm{H}_{2} \mathrm{O}_{2}$ sensor (HPP272). Gas-phase 2-methyl-2-butene $(<200 \mathrm{ppb})$ is introduced as a tracer to quantify the average $\mathrm{OH}$ concentration in the reactor. ${ }^{1,4}$ The total flow rate through the CFSTR was kept at $\sim 1.1$ SLM, yielding reaction times of hours. 


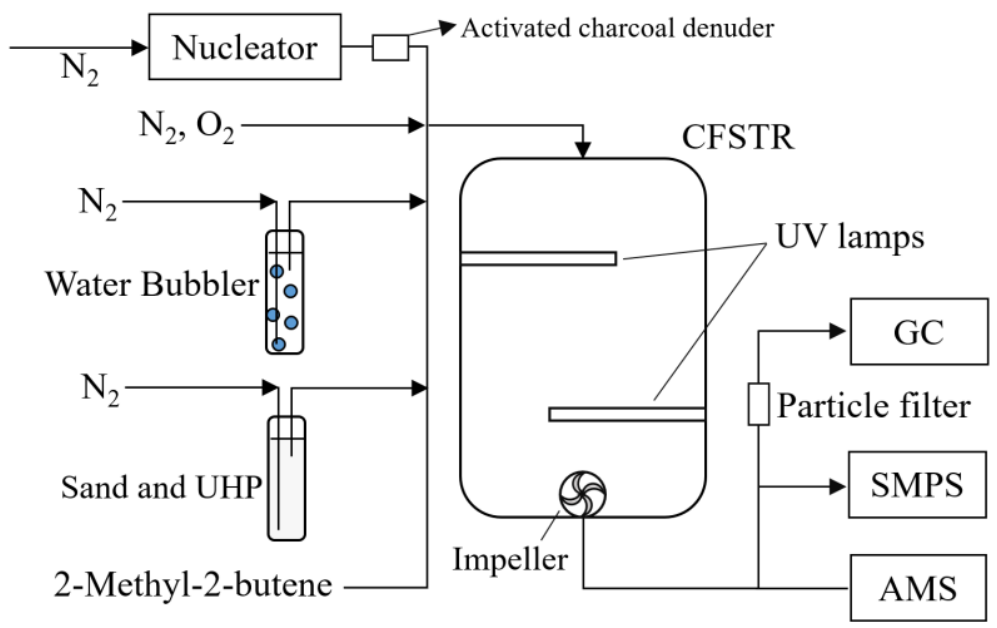

Figure S2. A schematic view of the continuous flow stirred tank reactor (CFSTR) used in the heterogeneous $\mathrm{OH}$ oxidation experiments. The UHP in the bubbler is urea-hydroperoxide. The GC, SMPS and AMS are gas chromatograph, scanning mobility particle sizer, and aerosol mass spectrometer, respectively.

The reactions are monitored using three detectors. The particle-size distribution is measured by a scanning mobility particle sizer (SMPS, TSI 3080L DMA and 3025A CPC). The decay of the gas-phase tracer, 2-methyl-2-butene, is measured using a gas chromatograph (GC, SRI Instruments $8610 \mathrm{C}$ with FID detection). The chemical composition of the aerosol is measured using a home-made vacuum ultraviolet aerosol mass spectrometer (VUV-AMS) ${ }^{5}$ located at the Chemical Dynamics Beamline (9.0.2), Advanced Light Source (ALS), Lawrence Berkeley National Laboratory, Berkeley, CA, USA. Due to the lack of photoionization cross-sections and ion fragmentation patterns, it is very hard to measure absolute concentrations of products. Instead, we use relative abundance (\%). The relative abundance for species $\mathrm{X}$ is normalized by the unreacted Tri (i.e. $[\mathrm{X}] /[$ Tri $]$ ) signal, which is used to compare with the simulated results produced by our kinetic model. Reaction products with mass-to-charge-ratio $(\mathrm{m} / \mathrm{z})<200$ are not shown since it is difficult to distinguish smaller reaction products from ion fragments of larger species produced by dissociative photoionization (e.g. possible ion fragments from $\alpha$-alkoxyalkyl hydroperoxides 
shown in Figs. S3 and S5). Additionally, smaller reaction products in this mass range are expected to be too volatile to remain in the aerosol. This experimental setup has been used extensively in prior studies of heterogeneous reactions and further details can be found in Refs. ${ }^{2-4,6}$.

\section{S1.2. Reaction scheme and product identification}

As shown in Figs. 3 and $\mathrm{S} 3$, ozonolysis of Tri $\left(\mathrm{C}_{23} \mathrm{H}_{46}\right)$ begins by the electrophilic addition of $\mathrm{O}_{3}$ to the $\mathrm{C}=\mathrm{C}$ bond in Tri. This produces a primary ozonide $\left(\mathrm{POZ}, \mathrm{C}_{23} \mathrm{H}_{46} \mathrm{O}_{3}\right)$, that undergoes bond scission to produce a $\mathrm{C}_{14}$ aldehyde $\left(\mathrm{C}_{14} \mathrm{H}_{28} \mathrm{O}\right)$ and a $\mathrm{C}_{9} \mathrm{CI}\left(\mathrm{C}_{9} \mathrm{H}_{18} \mathrm{O}_{2}\right)$, or a $\mathrm{C}_{9}$ aldehyde $\left(\mathrm{C}_{9} \mathrm{H}_{18} \mathrm{O}\right)$ and a $\mathrm{C}_{14} \mathrm{CI}\left(\mathrm{C}_{14} \mathrm{H}_{28} \mathrm{O}_{2}\right)$. The $\mathrm{C}_{9}$ and $\mathrm{C}_{14}$ aldehydes are volatile and evaporate easily into gas phase. The $\mathrm{C}_{9}$ and $\mathrm{C}_{14} \mathrm{CI}$ can react with $\mathrm{H}_{2} \mathrm{O}$ to produce $\alpha$-hydroxyalkyl hydroperoxides (HAH), which can be consumed via three unimolecular pathways ${ }^{7,8}$ as shown for the $\mathrm{C}_{14} \mathrm{CI}$ in Fig. S4. Bimolecular reactions of the $\mathrm{C} 9 \mathrm{CI}$ and the $\mathrm{C}_{14} \mathrm{CI}$ with the $\mathrm{CI}$ scavenger (2-octyl-1-dodecanol, $\left.\mathrm{C}_{20} \mathrm{H}_{42} \mathrm{O}\right)$ produce two $\alpha$-alkoxyalkyl hydroperoxides: $\mathrm{C}_{29} \mathrm{H}_{60} \mathrm{O}_{3}\left(\mathrm{C}_{29} \mathrm{AAH}\right)$ and $\mathrm{C}_{34} \mathrm{H}_{70} \mathrm{O}_{3}\left(\mathrm{C}_{34}\right.$ AAH), respectively.

AAH products are not detected as parent ions but at $m / z$ 's corresponding the elimination of $\mathrm{H}_{2} \mathrm{O}$ and $\mathrm{H}_{2} \mathrm{O}_{2}$ as described in Ref. ${ }^{2}$ and shown in Fig. S3. The $\mathrm{C}_{34} \mathrm{AAH}$ product exhibits additional fragmentation pathways as shown in Fig. S5. 2-Octyl-1-dodecanol is also not detected as its parent molecular ion $\left(\mathrm{C}_{20} \mathrm{H}_{42} \mathrm{O}, \mathrm{m} / z=298\right)$ but instead at a $m / z$ corresponding to $-\mathrm{H}_{2} \mathrm{O}$ loss $\left(\mathrm{C}_{20} \mathrm{H}_{40}, m / z=280\right)$. Unfortunately, as shown in Fig. S5, the $\mathrm{C}_{34} \mathrm{AAH}$ also has a fragment at $m / z$ $=280$, which prevents us from measuring the kinetic evolution of 2-octyl-1-dodecanol during the $\mathrm{Tri}+\mathrm{O}_{3}$ experiments. As previously noted, fragmentation in VUV aerosol mass spectra is quite sensitive to the aerosol vaporization temperature and photoionization energy. ${ }^{5}$ 

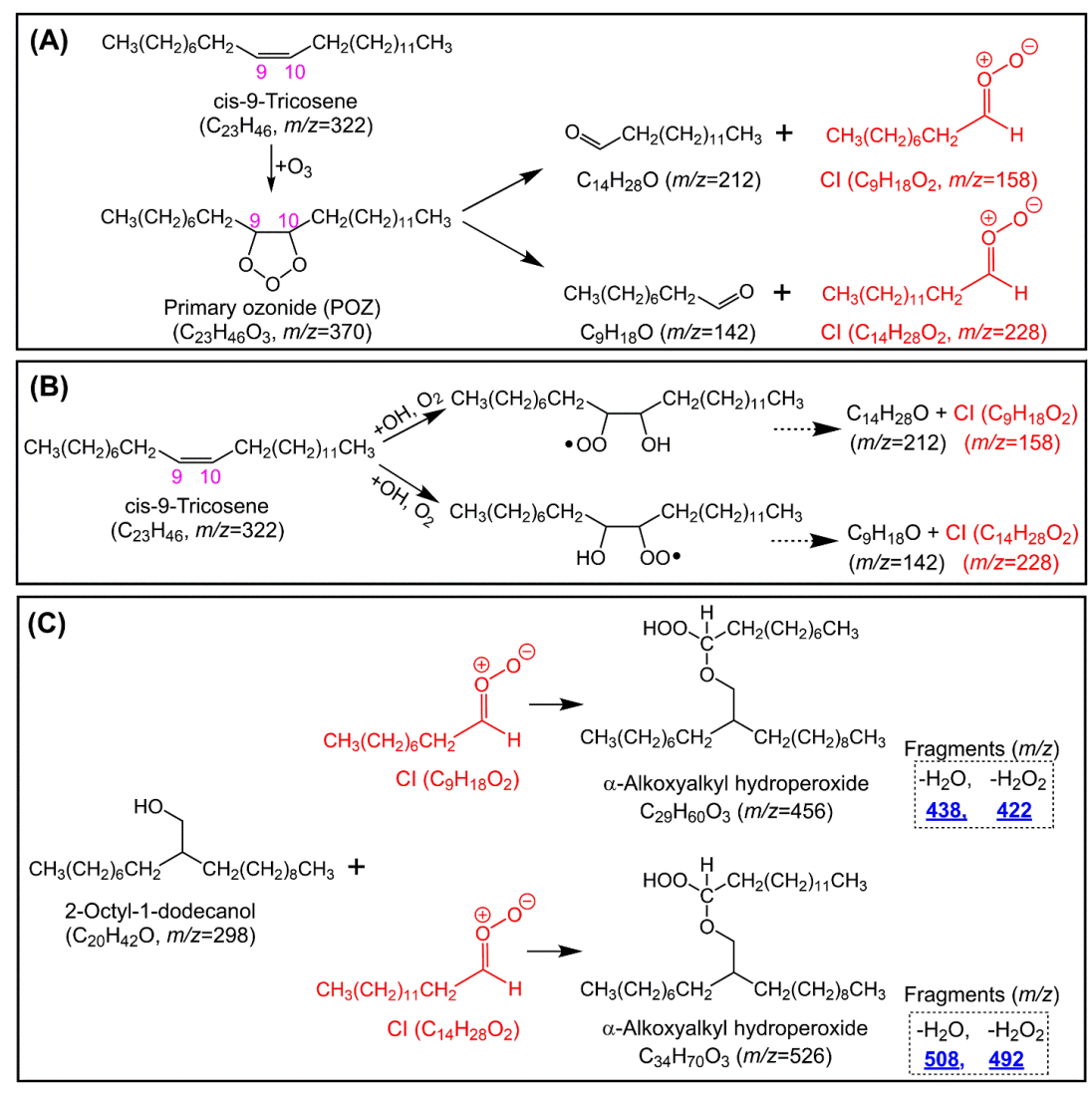

Figure S3. (A) Reaction pathways of cis-9-tricosene and ozone to produce CI and aldehydes. (B) Reaction pathways of cis-9-tricosene and $\mathrm{OH}$ to produce $\mathrm{CI}$ and aldehydes. (C) Reactions pathways of the CI scavenger (2-octyl-1-dodecanol) to produce two $\alpha$-alkoxyalkyl hydroperoxides. Also shown are the $\mathrm{m} / \mathrm{z}$ 's used for assignment in VUV-AMS mass spectrum.

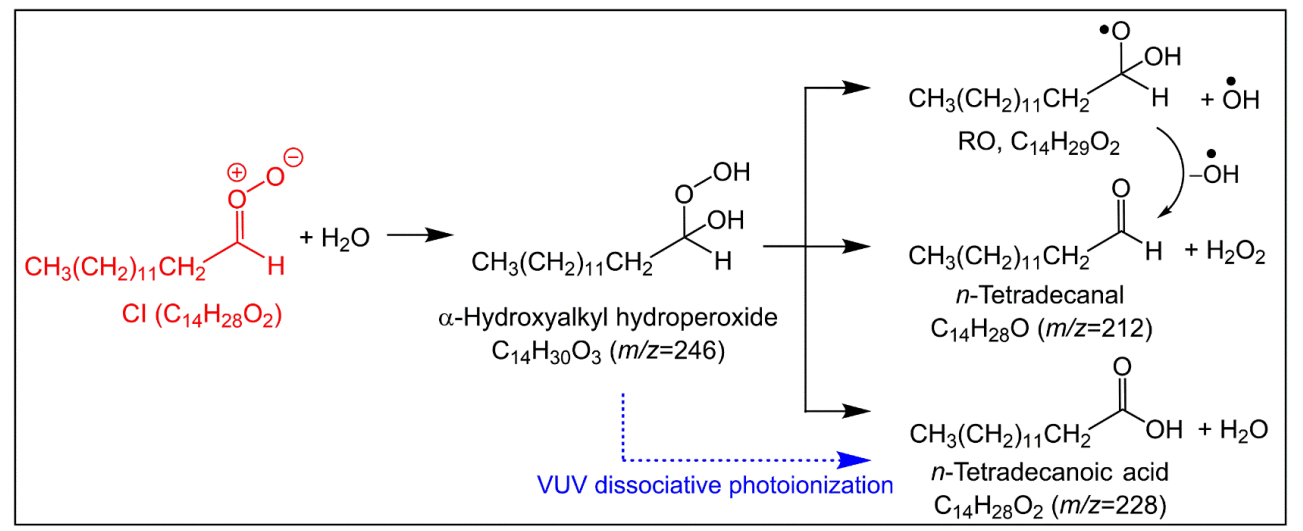

Figure S4. The reaction pathway of $\mathrm{C}_{14} \mathrm{CI}$ with $\mathrm{H}_{2} \mathrm{O}$ produces the $\mathrm{C}_{14} \alpha$-hydroxyalkyl hydroperoxide $\left(\mathrm{C}_{14} \mathrm{HAH}\right)$ and three unimolecular decomposition pathways of the $\mathrm{C}_{14} \mathrm{HAH}$. VUV dissociative photoionization of $\mathrm{C}_{14} \mathrm{HAH}$ can also generate the n-tetradecanoic acid and $\mathrm{H}_{2} \mathrm{O}$ as indicated by blue arrow. 


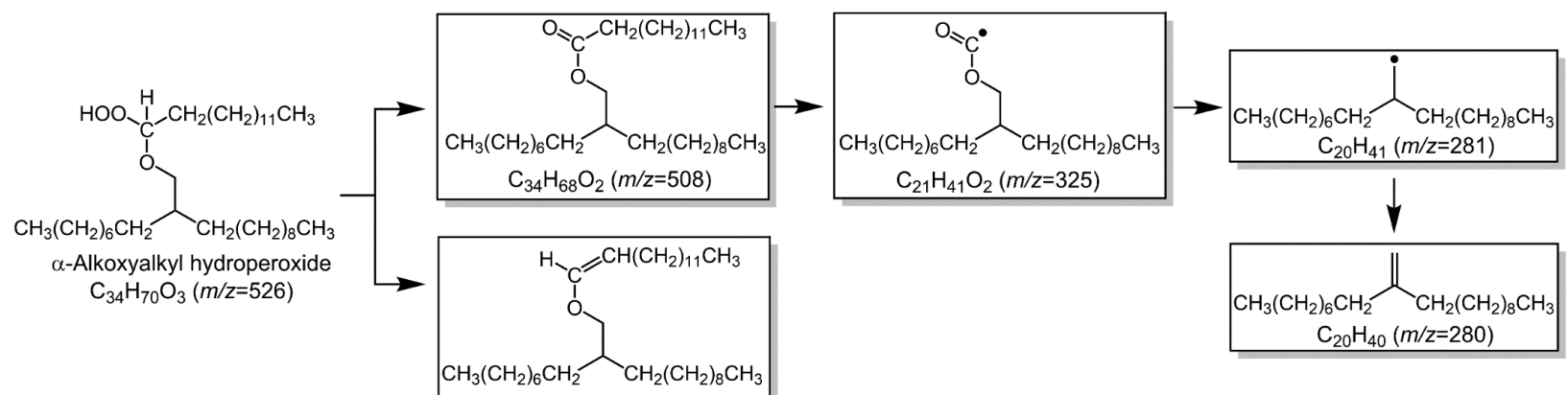

$\mathrm{C}_{34} \mathrm{H}_{68} \mathrm{O}(\mathrm{m} / \mathrm{z}=492)$

Figure S5. Fragmentation pathways of the $\mathrm{C}_{34} \alpha$-alkoxyalkyl hydroperoxide. Fragment $\mathrm{m} / \mathrm{z}$ 's are shown to justify their assignment in the VUV-AMS mass spectrum. Fragments are likely produced by dissociative photoionization.

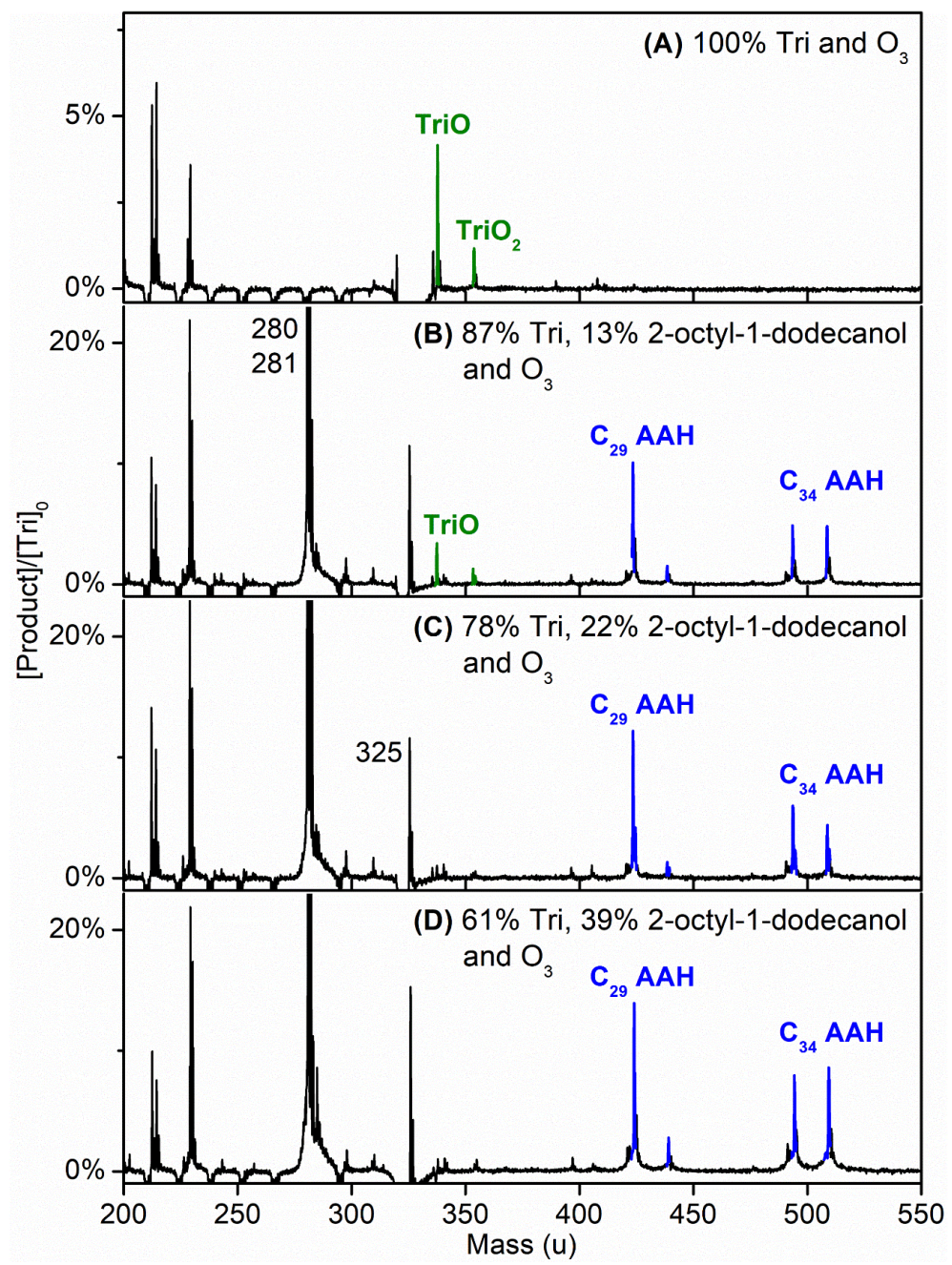


Figure S6. Difference mass spectra (unreacted Tri - reacted Tri) showing the major reaction products, such as ketone (TriO and $\mathrm{TriO}_{2}$ ) and $\alpha$-alkoxyalkyl hydroperoxide (AHH) during (A) the $100 \%$ Tri $+\mathrm{O}_{3}$ reactions; (B) 87\% Tri, 13\% 2-octyl-1-dodecanol $+\mathrm{O}_{3}$ reactions; (C) $78 \%$ Tri, 22\% 2-octyl-1-dodecanol $+\mathrm{O}_{3}$ reactions; (D) 61\% Tri, 39\% 2-octyl-1-dodecanol $+\mathrm{O}_{3}$ reactions.

\section{S1.3. Relative humidity dependence for $\mathrm{Tri}+\mathrm{O}_{3}$ reactions}

As shown in Fig. S7, the Tri $+\mathrm{O}_{3}$ reaction is measured under dry and wet (relative humidity $=60 \%$ ) conditions. As discussed in the main text, the concentrations of TriO and $\mathrm{TriO}_{2} \mathrm{decrease}$ with the addition of water vapor (Figs. 2B, S7A-S7B) since $\mathrm{H}_{2} \mathrm{O}$ acts as a CI scavenger via the bimolecular reaction shown in Fig. 3. However, in the presence of particle-phase alcohol, relative humidity does not change the observed intensities of the $\alpha$-alkoxyalkyl hydroperoxide (AAH) products (Figs. S7C-S7D). This shows that 2-octyl-1-dodecanol is a more effective CI scavenger than water.

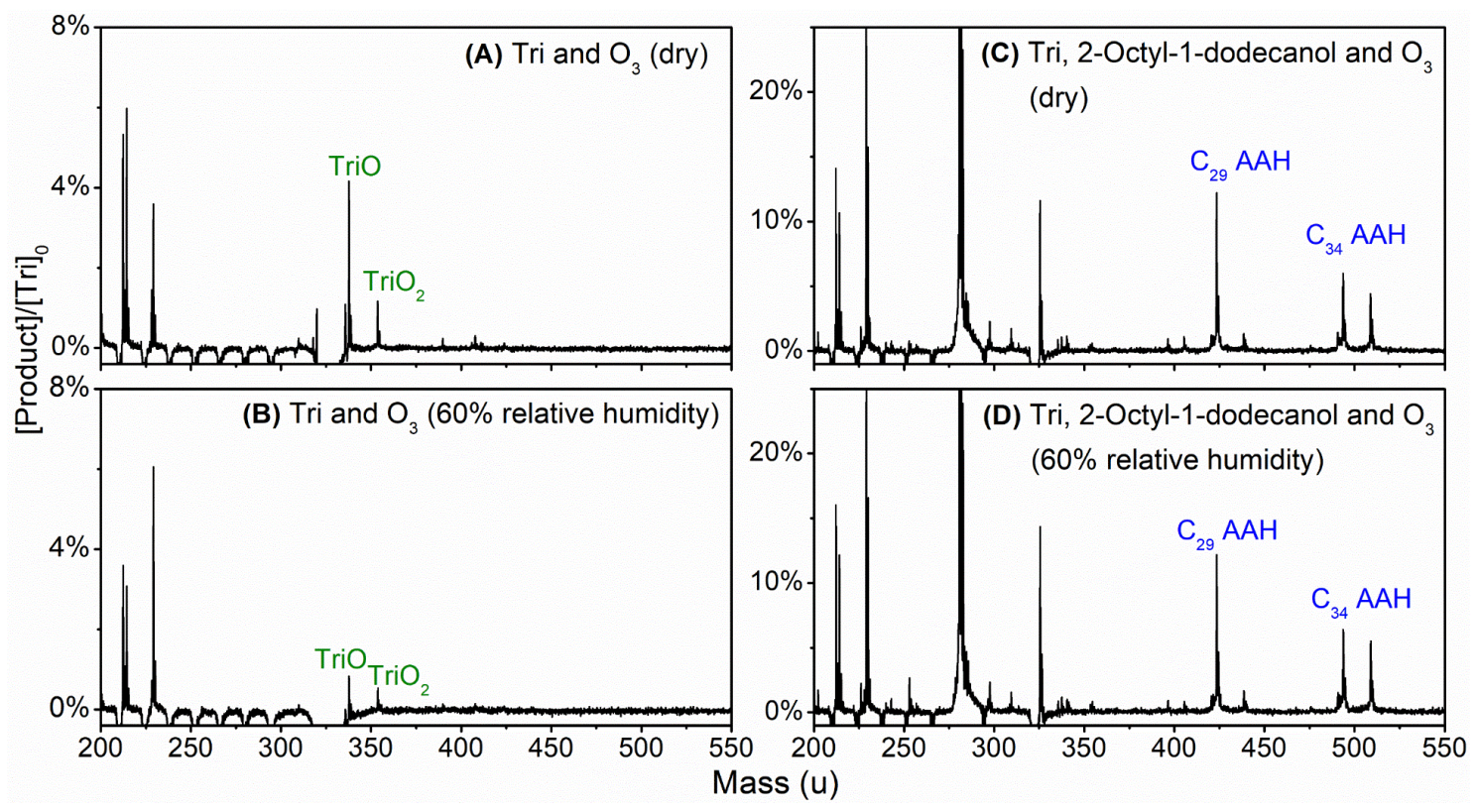

Figure S7. Difference VUV-AMS spectra (unreacted Tri - reacted Tri) observed in the Tri $+\mathrm{O}_{3}$ reactions (A and $\mathrm{B}$ ), and spectra recorded for the Tri/2-octyl-1-dodecanol $+\mathrm{O}_{3}$ reactions $(\mathrm{C}$ and D) under dry conditions and at $60 \%$ relative humidity $\left(\left[\mathrm{O}_{3}\right] \sim 4.0 \times 10^{13}\right.$ molecules $\left.\cdot \mathrm{cm}^{-3}\right)$. 


\section{S2. Supporting information for simulations}

\section{S2.1. Simulation methods and model development}

A chemical kinetic model is developed in Kinetiscope $\left({ }^{9}\right.$, which had been used extensively to model heterogeneous chemical reactions..$^{3,10-16}$ As shown previously for heterogeneous reactions with $\mathrm{OH}^{11-13,15,16}$ and $\mathrm{O}_{3}^{3,14}$, a single instantaneously mixed compartment is used to represent the aerosol, which is a valid assumption for a liquid that is well-mixed on reaction timescales. ${ }^{10}$ To properly account for surface-to-volume scaling in the spherical aerosols, the single compartment is represented by a $1 \mathrm{~nm} \times 1 \mathrm{~nm} \times(\mathrm{R} / 3) \mathrm{nm}$ rectangular volume, where $\mathrm{R}$ is the measured radius of the aerosol. Gas-phase $\mathrm{O}_{3}(\mathrm{or} \mathrm{OH}$ ) adsorption occurs in a $1 \mathrm{~nm}$ thick surface region as discussed in Ref. ${ }^{3}$. The model is comprised of three parts: (a) the adsorption of gas-phase $\mathrm{O}_{3}$ (or $\mathrm{OH}$ ) onto the surface of the aerosol; (b) condensed-phase chemical reactions and (c) evaporation of volatile products, such as the volatile aldehydes $\left(\mathrm{C}_{14} \mathrm{H}_{28} \mathrm{O}\right.$ and $\left.\mathrm{C}_{9} \mathrm{H}_{18} \mathrm{O}\right)$ in Fig. S3. How evaporation has been previously modeled is described in prior studies. ${ }^{3,13}$

(a) Adsorption of gas-phase $\mathrm{O}_{3}(\mathrm{or} \mathrm{OH})$

Here we assume a Langmuir Hinshelwood mechanism, where $\mathrm{OH}$ or $\mathrm{O}_{3}$ adsorbs to the surface prior to reaction and that there is one adsorption site per molecule. A pseudo-first order rate coefficient $\left(k_{\text {ads }}\right)$ is used to describe the adsorption of $\mathrm{O}_{3}$ (or $\mathrm{OH}$ ) onto the surface of the aerosols by using equations $\mathrm{S} 1$ for $\mathrm{O}_{3}$, and $\mathrm{S} 2$ for $\mathrm{OH}$, respectively.

$$
\begin{aligned}
& k_{a d s, O_{3}}=\left[O_{3}\right] \times Z \times S_{O_{3}} \\
& k_{a d s, O H}=[O H] \times Z \times S_{O H}
\end{aligned}
$$


Here, $\left[\mathrm{O}_{3}\right]$ and $[\mathrm{OH}]$ are the measured concentrations used in the experiment. $\mathrm{Z}$ is the collision frequency of $\mathrm{O}_{3}($ or $\mathrm{OH})$, which is $\sigma \times v \cdot \sigma$ is the collision cross-section of the surface (1 $\mathrm{nm} \times 1 \mathrm{~nm})$ and $v$ is the mean speed of ozone $\left(390 \mathrm{~m} \cdot \mathrm{s}^{-1}\right)$ or $\mathrm{OH}\left(610 \mathrm{~m} \cdot \mathrm{s}^{-1}\right) . S$ is the sticking coefficient of $\mathrm{O}_{3}$ (or $\left.\mathrm{OH}\right)$. The sticking coefficient of $\mathrm{O}_{3}\left(S_{O_{3}}\right)$ used in the model is $2.4 \times 10^{-5}$, which is within the range $\left(10^{-5} \sim 10^{-4}\right)$ reported in the Refs. ${ }^{17,18}$. It is smaller than the value $(1.8 \times$ $10^{-4}$ ) used previously to model the $\mathrm{Sqe}+\mathrm{O}_{3}$ reaction $^{3}$ and is roughly consistent with the difference in the number of $\mathrm{C}=\mathrm{C}$ bonds in Sqe (6 $\mathrm{C}=\mathrm{C}$ bonds) vs. Tri. The sticking coefficient of $\mathrm{OH}(\mathrm{SOH})$ used in present model is estimated to be 0.2 , in order to achieve a global agreement between simulations and experiments as shown in Fig. S11. The rate constants for the adsorption are shown in Table S1.

\section{(b) Condensed-phase chemical reactions}

Shown in Table S1 are the elementary reaction steps used in the model, which reflect the three sub-mechanisms shown schematically in Fig. 3. A discussion and analysis of additional reactions that are not included in the model can be found in Section S2.2. References for the rate coefficients are also shown in Table S1. We use the general notation of RH to represent stable molecules (e.g. RH = Tri). The sub-mechanism for the heterogeneous ozonolysis of alkenes is quite well-known and is taken from prior work. . $^{3,14,19,20}$ One lumped reaction step (R1), which neglects the explicit formation/decomposition of the POZ, is used to form the CI and aldehyde $(\mathrm{C}=\mathrm{O})$ consistent with previous models of ozonolysis. ${ }^{3}$

The $\mathrm{CI}$ is consumed via four main pathways (R2-R5). The unimolecular reaction of CI produces an alkoxy radical $(\mathrm{RO})$ and $\mathrm{OH}(\mathrm{R} 2)$. Bimolecular steps of $\mathrm{CI}$ include reaction with the CI scavenger (2-octyl-1-dodecanol, ROH) to produce $\alpha$-alkoxyalkyl hydroperoxide (AAH), 
reaction with $\mathrm{O}_{3}$ produce a ketone $(\mathrm{C}=\mathrm{O})$, and reaction with $\mathrm{H}_{2} \mathrm{O}$ produce $\alpha$-hydroxyalkyl hydroperoxide (HAH). The consumption pathways of HAH are mainly its unimolecular reaction to produce an $\mathrm{RO}$ and $\mathrm{OH}$, or to produce ketone and $\mathrm{H}_{2} \mathrm{O}_{2}{ }^{7,8}$ The bimolecular reaction of $\mathrm{CI}$ with aldehydes to produce a secondary ozonide (SOZ) is neglected since they are not detected in the experiment.

The radical sub-mechanism includes $\mathrm{OH}$, alkoxy $(\mathrm{RO})$ and peroxy $\left(\mathrm{RO}_{2}\right)$ radical reactions (R6-R13). Elementary $\mathrm{OH}$ steps include $\mathrm{H}$-abstraction (R6) and $\mathrm{OH}$-addition (R7). H-abstraction by RO is shown in step R8. The addition of RO to Tri is not considered since the experiment yielded no evidence for products that would be produced by this reaction.

The alkyl radical (R), produced by H-abstraction reactions, and the hydroxy alkyl radical ( $\left.\mathrm{R}_{-} \mathrm{OH}\right)$, produced from the $\mathrm{OH}$-addition reactions, contribute to the formation of peroxy radical $\left(\mathrm{RO}_{2}\right)$ and $\beta$-hydroxy-peroxy radical $\left(\beta-\mathrm{RO}_{2}\right)$, respectively. $\mathrm{O}_{2}$ addition to these alkyl radicals, is described as pseudo first order, as shown in R9 and R10. Peroxy radical steps include self-reactions (i.e. $\mathrm{RO}_{2}+\mathrm{RO}_{2}$ ) form stable ketone and alcohol (R11) products or two alkoxy radicals (R12).

The $\beta$-hydroxy-peroxy radical $\left(\beta-\mathrm{RO}_{2}\right)$ decomposes to form a $\mathrm{CI}(\mathrm{R} 13)$ as reported by Beauchamp and coworkers. ${ }^{21,22}$ However, we lack theoretical calculations or experiments to constrain this rate constant. Thus this is an adjustable parameter in the model. We assume this step is unimolecular and a value of $120 \mathrm{~s}^{-1}$ produces model results in reasonable agreement with the global data set. We note that $\mathrm{H}_{2} \mathrm{O}$ (or $\mathrm{O}_{2}$ ) could facilitate this reaction as suggested in $\mathrm{Ref}^{21}$. Thus, further theoretical study is needed to provide more stringent constrains for this reaction step. 
Table S1. Reaction scheme and rate coefficients for stochastic simulations.

\begin{tabular}{|c|c|c|c|}
\hline No. & Reactions & Rate constant & Notes \\
\hline & $\mathrm{O}_{3}$ gas $\rightarrow \mathrm{O}_{3}$ _ads & $0.37 \mathrm{~s}^{-1}$ & $a$ \\
\hline & $\mathrm{OH}$ gas $\rightarrow$ OH_ads & $1.96 \times 10^{-3} \mathrm{~s}^{-1}$ & $a$ \\
\hline $\mathrm{R} 1$ & $\mathrm{RH}+\mathrm{O}_{3} \rightarrow \mathrm{CI}+\mathrm{C}=\mathrm{O}$ & $2.00 \times 10^{-16} \mathrm{~cm}^{3} \cdot \mathrm{molec}^{-1} \cdot \mathrm{s}^{-1}$ & Ref. $^{3}$ \\
\hline R2 & $\mathrm{CI} \rightarrow \mathrm{RO}+\mathrm{OH}$ & $205 \mathrm{~s}^{-1}$ & Ref. $^{23}$ \\
\hline R3 & $\mathrm{CI}+\mathrm{ROH} \rightarrow \mathrm{AAH}$ & $6.70 \times 10^{-19} \mathrm{~cm}^{3} \cdot \mathrm{molec}^{-1} \cdot \mathrm{s}^{-1}$ & $b$ \\
\hline R4 & $\mathrm{CI}+\mathrm{O}_{3} \rightarrow \mathrm{C}=\mathrm{O}$ & $4.00 \times 10^{-13} \mathrm{~cm}^{3} \cdot$ molec $^{-1} \cdot \mathrm{s}^{-1}$ & Ref..$^{3}$ \\
\hline R5 & $\mathrm{CI}+\mathrm{H}_{2} \mathrm{O} \rightarrow \mathrm{HAH}$ & $2.17 \mathrm{~s}^{-1}$ & $c$ \\
\hline \multicolumn{4}{|c|}{ Triggered radical chemistry } \\
\hline R6 & $\mathrm{RH}+\mathrm{OH} \rightarrow \mathrm{R}+\mathrm{H}_{2} \mathrm{O}$ & $2.00 \times 10^{-11} \mathrm{~cm}^{3} \cdot \mathrm{molec}^{-1} \cdot \mathrm{s}^{-1}$ & $d$ \\
\hline R7 & $\mathrm{RH}+\mathrm{OH} \rightarrow \mathrm{R} \_\mathrm{OH}$ & $6.60 \times 10^{-11} \mathrm{~cm}^{3} \cdot \mathrm{molec}^{-1} \cdot \mathrm{s}^{-1}$ & Ref. $^{24}$ \\
\hline $\mathrm{R} 8$ & $\mathrm{RH}+\mathrm{RO} \rightarrow \mathrm{R}+\mathrm{ROH}$ & $1.66 \times 10^{-15} \mathrm{~cm}^{3} \cdot \mathrm{molec}^{-1} \cdot \mathrm{s}^{-1}$ & Ref. $^{25}$ \\
\hline R9 & $\mathrm{R}+\mathrm{O}_{2} \rightarrow \mathrm{RO}_{2}$ & $1.10 \times 10^{6} \mathrm{~s}^{-1}$ & $e$ \\
\hline $\mathrm{R} 10$ & $\mathrm{R} \_\mathrm{OH}+\mathrm{O}_{2} \rightarrow \beta-\mathrm{RO}_{2}$ & $1.10 \times 10^{6} \mathrm{~s}^{-1}$ & $e$ \\
\hline R11a & $\mathrm{RO}_{2}+\mathrm{RO}_{2} \rightarrow \mathrm{RC}=\mathrm{O}+\mathrm{ROH}$ & $4.00 \times 10^{-15} \mathrm{~cm}^{3} \cdot$ molec $^{-1} \cdot \mathrm{s}^{-1}$ & Ref. $^{25}$ \\
\hline $\mathrm{R} 11 \mathrm{~b}$ & $\beta-\mathrm{RO}_{2}+\beta-\mathrm{RO}_{2} \rightarrow \mathrm{RC}=\mathrm{O}+\mathrm{ROH}$ & $4.00 \times 10^{-15} \mathrm{~cm}^{3} \cdot \mathrm{molec}^{-1} \cdot \mathrm{s}^{-1}$ & Ref. $^{25}$ \\
\hline $\mathrm{R} 12$ & $\mathrm{RO}_{2}+\mathrm{RO}_{2} \rightarrow \mathrm{RO}+\mathrm{RO}+\mathrm{O}_{2}$ & $1.00 \times 10^{-16} \mathrm{~cm}^{3} \cdot$ molec. $^{-1} \cdot \mathrm{s}^{-1}$ & $\operatorname{Ref.}^{25}$ \\
\hline $\mathrm{R} 13$ & $\beta-\mathrm{RO}_{2} \rightarrow \mathrm{CI}+\mathrm{R} \_\mathrm{OH}$ & $120 \mathrm{~s}^{-1}$ & $f$ \\
\hline
\end{tabular}

Note: ${ }^{a}$ Rate coefficients depend on the $[\mathrm{OH}]$ or $\left[\mathrm{O}_{3}\right]$ concentration; ${ }^{b}$ Rate coefficient is the same as the reaction of CI with aldehydes to produce secondary ozonides from Ref. ${ }^{3}$; ${ }^{c}$ Treated as pseudo-first-order rate constant where $\left[\mathrm{H}_{2} \mathrm{O}\right]=3 \%$ for dry condition, $k=4.3 \times 10^{-15} \mathrm{~cm}^{3} \cdot \mathrm{molec}$.' ${ }^{1} \cdot \mathrm{s}^{-1}$ from Ref. ${ }^{23}$. ${ }^{d}$ Rate coefficients for the $\mathrm{H}$-abstraction reaction are calculated from the structure-activity relationship (SAR) in Refs. ${ }^{26,27}$, such as $2.00 \times 10^{-11} \mathrm{~cm}^{3} \cdot \mathrm{molec}^{-1} \cdot \mathrm{s}^{-1}$ for Tri and $\mathrm{OH} .{ }^{e}$ Treated as pseudo-first-order rate constant where $\left[\mathrm{O}_{2}\right]=10 \%, k=2.5 \times 10^{-12}$ $\mathrm{cm}^{3} \cdot$ molec. $^{-1} \cdot \mathrm{s}^{-1}$ from Refs. ${ }^{10,25} \cdot{ }^{f}$ Estimated in this work, see text for details.

\section{S2.2. Additional mechanistic tests of the model}

In addition to the reactions included in the base model shown in Table S1 (Section S2.1), below we evaluate the possible importance of a number of other pathways involving $\mathrm{CI}, \mathrm{RO}_{2}$ and 
RO. These steps are shown in Table S2 and are denoted Test_R1-5. These reaction steps are individually added to the base model (Table $\mathrm{S} 1)$ to produce a new test model. The relative kinetic importance of these reactions are then evaluated by comparing the output from the test model with experimental observations and the base model predictions as discussed below.

Table S2. Additional reaction types (named as Test_R) and rate coefficients used in the test model.

\begin{tabular}{l|l|l|l}
\hline No. & Reactions in Test model & Rate constant & Notes \\
\hline Test_R1 & CI + Tri $\rightarrow$ CHP & $7.0 \times 10^{-16} \mathrm{~cm}^{3} \cdot \mathrm{molec}^{-1} \cdot \mathrm{s}^{-1}$ & Ref..${ }^{28}$ \\
\hline Test_R2 & $\mathrm{RO}_{2}+$ Tri $\rightarrow$ RO + Epoxide & $1.66 \times 10^{-21} \mathrm{~cm}^{3} \cdot \mathrm{molec}^{-1} \cdot \mathrm{s}^{-1}$ & Ref..${ }^{29}$ \\
\hline Test_R3 & $\mathrm{RO}_{2}+$ Tri $\rightarrow$ ROOH + Tri_R & $2.3 \times 10^{-21} \mathrm{~cm}^{3} \cdot \mathrm{molec}^{-1} \cdot \mathrm{s}^{-1}$ & Ref.. \\
\hline Test_R4 & Tri_RO $\rightarrow$ Tri_QOOH & $5 \times 10^{-4} \mathrm{~s}^{-1}$ & Ref. $^{30}$ \\
\hline Test_R5 & RO $\rightarrow$ Unimolecular decomposition & See text & Refs. ${ }^{31,32}$ \\
\hline
\end{tabular}

Reaction of CI with alkenes. In the gas phase CI react with alkenes to produce a five membered cyclic hydroperoxide (CHP). ${ }^{28,33}$ Given the high concentration of Tri in the particle we evaluate the potential importance of these reactions for the present work shown as Test_R1 in Table S2. The reaction of the $\mathrm{C}_{9}$ and $\mathrm{C}_{14} \mathrm{CI}\left(\mathrm{C}_{9} \mathrm{H}_{18} \mathrm{O}_{2}\right.$ and $\mathrm{C}_{14} \mathrm{H}_{28} \mathrm{O}_{2}$, Fig. S3) with Tri $\left(\mathrm{C}_{23} \mathrm{H}_{46}\right)$ would produce a $\mathrm{C}_{32} \mathrm{CHP}$ and $\mathrm{C}_{37} \mathrm{CHP}$, i.e. $\mathrm{C}_{9} \mathrm{H}_{18} \mathrm{O}_{2}+\mathrm{C}_{23} \mathrm{H}_{46} \rightarrow \mathrm{C}_{32} \mathrm{H}_{64} \mathrm{O}_{2}$; and $\mathrm{C}_{14} \mathrm{H}_{28} \mathrm{O}_{2}+$ $\mathrm{C}_{23} \mathrm{H}_{46} \rightarrow \mathrm{C}_{37} \mathrm{H}_{74} \mathrm{O}_{2}$. These two reactions are added to the base model (Table S1) and a new simulation is conducted (termed test model). The rate constant used for these steps is $7.0 \times 10^{-16}$ $\mathrm{cm}^{3} \cdot \mathrm{molec}^{-1} \cdot \mathrm{s}^{-1}$ as reported in Ref. ${ }^{28}$ As shown in Fig. S8, the simulated concentrations of TriO and AAH in the test model are much lower (i.e. near zero) than experimental observations and the predictions of the base model, which lacks the $\mathrm{CI}+$ Tri reaction. As shown with reaction step markers in Fig. S8A, the consumption of the CI is dominated by the CI + Tri reactions. When included the CI + Tri pathways outcompete unimolecular decomposition of the CI, effectively 
shutting off free radical production, which is the source of TriO as shown in Figs. S8A and S8B.

This is also the case for AAH production shown in Fig. S8C, where the reactions of CI + 2-octyl1-dodecanol cannot compete with Tri + CI.

We find no evidence for the production of the $\mathrm{C}_{32} \mathrm{CHP}(\mathrm{m} / \mathrm{z}=480)$ and $\mathrm{C}_{37} \mathrm{CHP}(\mathrm{m} / \mathrm{z}=$ 550) products in the mass spectrum (e.g. Fig. 1). This is consistent with many previous studies, which do not report evidence for this reaction or the formation of CHP during the heterogeneous ozonolysis of unsaturated compounds..$^{3,19,20,34-36}$ Thus, these reaction steps are not included in the base model shown in Table S1.
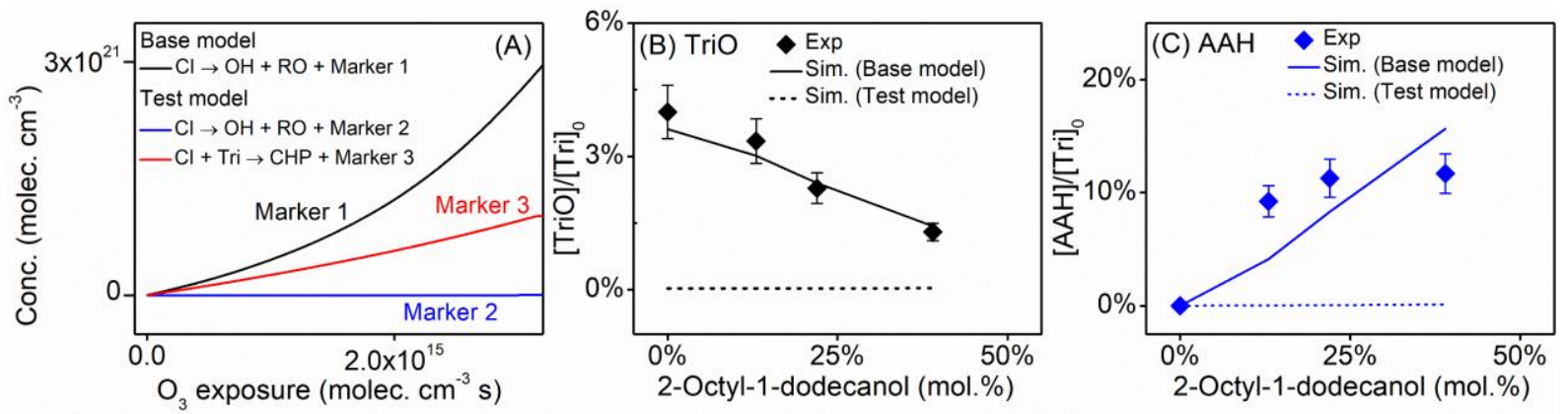

Figure S8. (A) Simulated concentrations and reaction markers for two competitive consumption pathways of CI in the base model (Table S1), and the test model (Table S1 + (Tri + CI reactions)) during the Tri $+\mathrm{O}_{3}$ reactions. (B and $\mathbf{C}$ ) Experimental (symbols) and simulated (lines) concentrations of TriO and AAH. Solid and dash lines are simulations by the base model and test model, respectively.

Reaction of $\mathrm{RO}_{2}$ with alkenes. $\mathrm{RO}_{2}$ can react with an alkene to produce a $\mathrm{RO}$ and epoxide as discussed in Ref. $^{29}$. To evaluate the effects of including this reaction type in the simulations, the reactions of $\mathrm{RO}_{2}$ with Tri to produce a $\mathrm{RO}$ and an epoxide (i.e. $\mathrm{RO}_{2}+$ Tri $\rightarrow \mathrm{RO}+$ epoxide, Test_R2 in Table S2) are added to the base model. The rate constant for this reaction type is 1.66 $\times 10^{-21} \mathrm{~cm}^{3} \cdot \mathrm{molec}^{-1} \cdot \mathrm{s}^{-1}$ from Ref. ${ }^{29}$. The results of simulations with and without this reaction type are nearly identical as shown in Fig. S9A. For example, the relative contribution of the $\mathrm{RO}_{2}+$ Tri reactions to the consumption of Tri is $\sim 0.5 \%$, compared with contributions from other reactions 
(Fig. 4), i.e. the Tri $+\mathrm{O}_{3}$, Tri $+\mathrm{OH}$, and Tri $+\mathrm{RO}$ reactions. The relative contribution of this reaction type to the consumption of $\mathrm{RO}_{2}$ is $\sim 1 \%$, compared with competing reactions such as the bimolecular reaction of two $\mathrm{RO}_{2}$. The concentration of the epoxide from this reaction type is also negligible. Given that this reaction type plays a minor role under our experimental conditions, we have not included this reaction type in the base model shown in Table S1.
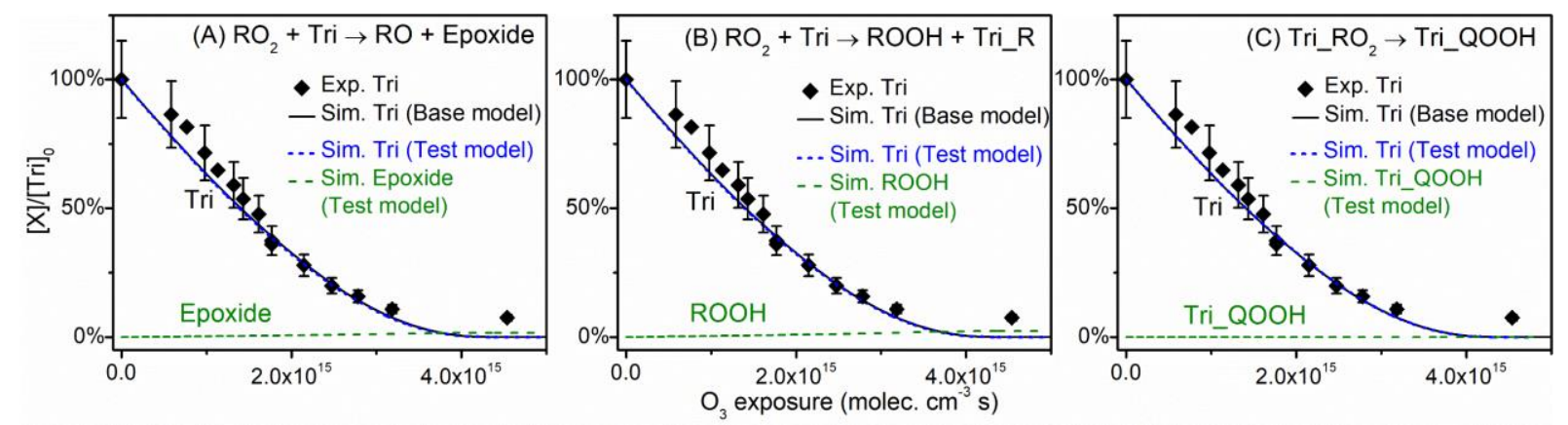

Figure S9. Experimental (symbols) and simulated (lines) concentrations of Tri, (A) Epoxide, (B) $\mathrm{ROOH}$ and $(\mathbf{C})$ Tri_QOOH during the Tri $+\mathrm{O}_{3}$ reactions. Solid lines are simulations by the base model. Dash lines are simulations by the test model, which includes (A) Test_R2, $\mathrm{RO}_{2}+$ Tri $\rightarrow$ RO + Epoxide; $(\mathbf{B})$ Test_R3, $\mathrm{RO}_{2}+$ Tri $\rightarrow \mathrm{ROOH}+$ Tri_R; (C) Test_R4, Tri_RO $2 \rightarrow$ Tri_QOOH, respectively.

H-abstraction by $\mathbf{R O}_{2}$. H-abstraction reactions of organic molecules by $\mathrm{RO}_{2}$ (e.g. Tri) produce a hydroperoxide $(\mathrm{ROOH})$ and alkyl radical $(\mathrm{R})$ as discussed in Refs. ${ }^{25,37,38}$ To test the importance of this reaction type in the simulations under our reaction conditions, the reactions of the $\mathrm{RO}_{2}$ with Tri to produce the $\mathrm{ROOH}$ and the Tri alkyl radical (i.e. $\mathrm{RO}_{2}+$ Tri $\rightarrow \mathrm{ROOH}+$ Tri_R, Test_R3 in Table S2) are added to the base model shown in Table S1. The rate constant $\left(2.3 \times 10^{-}\right.$ ${ }^{21} \mathrm{~cm}^{3} \cdot$ molec. $\left.^{-1} \cdot \mathrm{s}^{-1}\right)$ is estimated from Ref. ${ }^{25}$ The inclusion of these reaction steps do not alter the predictions of the base model as shown in Fig. S9B. For example, the relative contributions of this reaction type $\left(\mathrm{RO}_{2}+\right.$ Tri) to the consumption of $\mathrm{RO}_{2}$ and Tri are small $(\sim 1 \%)$. Thus, for simplicity these reactions are not included in the base model (Table S1). 
Isomerization of $\mathbf{R O}_{2} \rightarrow \mathbf{Q O O H}$. The isomerization reaction of $\mathrm{RO}_{2}$, via an internal $\mathrm{H}$ shift, can produce a hydroperoxyalkyl radical (QOOH) as discussed in Refs. ${ }^{30,39}$. To test the effects of including this reaction type (Test_R4 in Table S2), the isomerization of Tri peroxy radical (Tri_RO 2 ) to produce a Tri hydroperoxyalkyl radical (Tri_QOOH) is added into a test model using the rate constant $\left(5 \times 10^{-4} \mathrm{~s}^{-1}\right)$ from Ref. ${ }^{30}$ Test model simulations show that the relative contribution of this reaction to the consumption of Tri_ $\mathrm{RO}_{2}$ is negligible $(\sim 0 \%)$, compared with the competing bimolecular Tri_RO $\mathrm{RO}_{2}+\mathrm{RO}_{2}$ (e.g. Tri_ $\left.\mathrm{RO}_{2}\right)$ reactions. The simulated concentration of Tri_QOOH by the test model is also negligible $(\sim 0 \%)$ as shown in Fig. S9C.

Unimolecular decomposition of RO. The unimolecular decomposition of the $\mathrm{C}_{9}$ and $\mathrm{C}_{14}$ CI can produce $\mathrm{OH}$ and conjugated RO radicals as shown in Fig. S10. Three unimolecular decomposition reactions of RO are possible (Fig. S10 and Test_R5 in Table S2) based on Refs. ${ }^{31,32}$ The $\beta$-C-C scission reaction of the $\mathrm{C}_{9} \mathrm{RO}$ to produce a hexyl $\left(\mathrm{C}_{6} \mathrm{R}\right)$ radical and acrolein $\left(\mathrm{C}_{3} \mathrm{H}_{4} \mathrm{O}\right)$ is similar to the $\beta$-C-C scission of n-butyl $\left(k=1.2 \times 10^{-8} \mathrm{~s}^{-1}\right.$ from $\left.\mathrm{Ref}^{32}\right)$. The remaining two reactions, in Fig. $\mathrm{S} 10$, of the $\mathrm{C}_{9} \mathrm{RO}$ to produce $\mathrm{C}_{9} \mathrm{H}_{16} \mathrm{O}$ and $\mathrm{H}$, or to produce $\mathrm{C}_{8} \mathrm{H}_{16}$ and $\mathrm{HCO}$ are analogous to $\mathrm{C}_{3} \mathrm{H}_{5} \mathrm{O}\left(\mathrm{CH}_{3} \mathrm{CHCHO}\right)$ reactions, which have rate coefficient of $1.66 \times 10^{-22}$ and 3.5 $\times 10^{-18} \mathrm{~s}^{-1}$ from Ref. ${ }^{31}$, respectively. As shown in $\mathrm{R} 8$ in Table $\mathrm{S} 1$, the rate constant for the bimolecular reaction of the RO with Tri via $\mathrm{H}$-abstraction is $1.66 \times 10^{-15} \mathrm{~cm}^{3} \cdot$ molecules $^{-1} \cdot \mathrm{s}^{-1}$. The pseudo-first-order rate constant for R8 is $\sim 2.5 \times 10^{6} \mathrm{~s}^{-1}$ with the [Tri]o of $1.5 \times 10^{21} \mathrm{molec} \cdot \mathrm{cm}^{-3}$. This rate is several orders of magnitude faster than the unimolecular decomposition reactions of RO (Fig. S10); showing that the main sink for RO, under our experimental conditions, is bimolecular $\mathrm{H}$ abstraction. Thus unimolecular decomposition reactions of RO were not included in the base model shown in Table S1. 


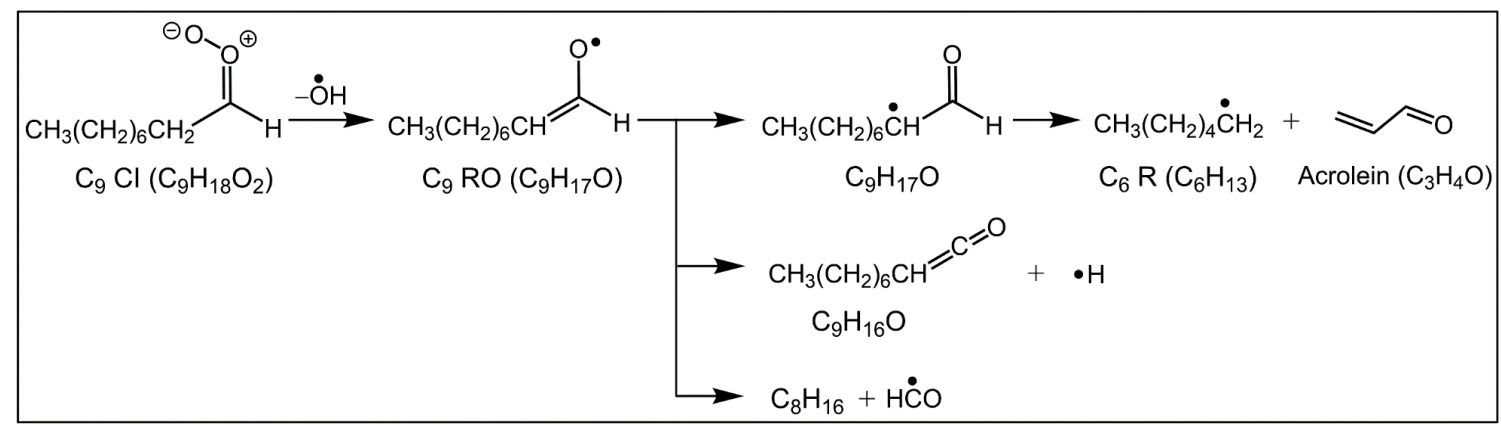

Figure S10. The unimolecular decomposition reaction of $\mathrm{C}_{9} \mathrm{CI}$ produces $\mathrm{OH}$ and the conjugated $\mathrm{C}_{9} \mathrm{RO}$. Three unimolecular decomposition pathways of $\mathrm{C}_{9} \mathrm{RO}$.

\section{S2.3. Simulation results for $\mathrm{Tri}+\mathrm{OH}$ reactions in the CFSTR}

As discussed in the main text, in order to isolate radical reactions $\left(\mathrm{OH}-\mathrm{RO}-\mathrm{RO}_{2}\right)$ from $\mathrm{O}_{3}$ chemistry, we first evaluate the model against the experimental observations for the Tri $+\mathrm{OH}$ reaction (without $\mathrm{O}_{3}$ ). These experiments are conducted in a continuous flow stirred tank reactor (CFSTR). As described by Che et al. ${ }^{1}$ and reviewed briefly here, measurements in the CFSTR occur in two steps. The reactor is first filled with the fresh reagents (aerosols, gas-phase $\mathrm{H}_{2} \mathrm{O}_{2}$, gasphase tracer 2-methyl-2-butene, dry or humidified $\mathrm{N}_{2}, \mathrm{O}_{2}$ ) with lamps off. After a $\sim 2$ hours of filling, the lamps are turned on to initiate the reaction by the photolysis of $\mathrm{H}_{2} \mathrm{O}_{2}$ to produce $\mathrm{OH}$. During the reaction there is a constant flow of reagents into the reactor as well as products and reactants exiting the reactor. Thus, in order account for this, two additional steps (S4 and S5) are added into the model to account for the continuous flow as described by Richards-Henderson et al. ${ }^{15}$. The rate constants for the flow process (S4 and S5) are the same $\left(\sim 10^{-4} \mathrm{~s}^{-1}\right)$ and are measured by quantifying the rate of increase of aerosol mass while filling an empty chamber ${ }^{1}$.

$$
\begin{aligned}
& \text { Fill } \rightarrow \text { Tri }+ \text { Fill } \\
& \text { Tri } \rightarrow \text { out }
\end{aligned}
$$


The model prediction is compared to Tri $+\mathrm{OH}$ experiments conducted at three different $[\mathrm{OH}]$ in CFTSR as shown in Fig. S11. In the experiment, the peak in the mass spectrum corresponding to TriO appears to have two contributions: TriO $\left(\mathrm{C}_{23} \mathrm{H}_{44} \mathrm{O}\right)$ and a fragment ion produced by dissociative photoionization $\left(-\mathrm{H}_{2} \mathrm{O}\right.$ loss $)$ of Tri_OH_CO $\left(\mathrm{C}_{23} \mathrm{H}_{46} \mathrm{O}_{2}\right)$. Thus to more closely compare with experiment, the modeled TriO species are a sum of tricosenyl ketone (TriO) and hydroxy-tricosenyl ketone (Tri_OH_CO) products. Overall, the model predictions are in reasonable agreement with experimental results.

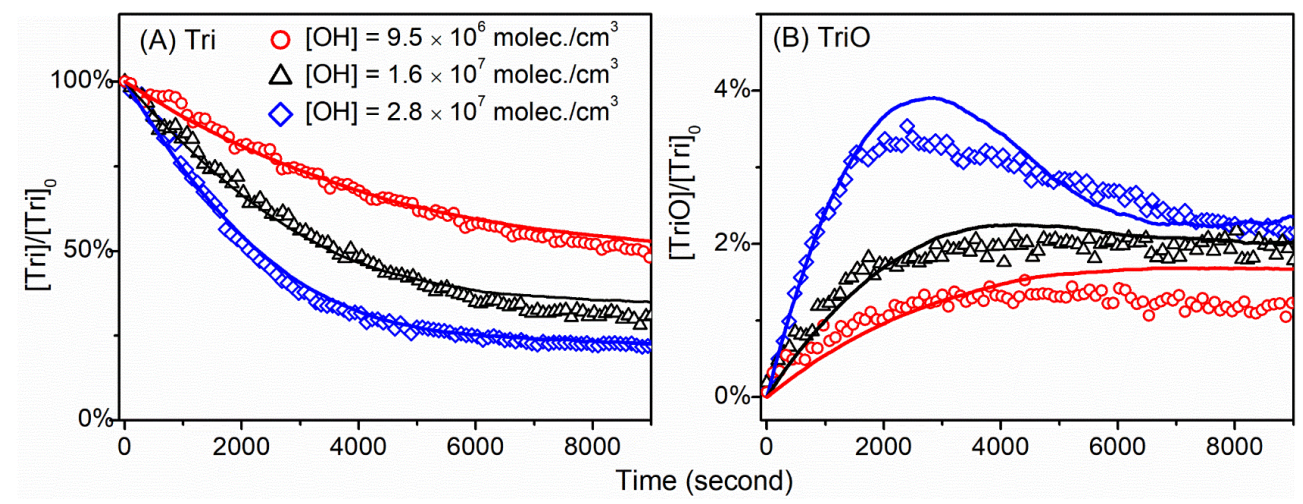

Figure S11. Experimental (symbols) and simulated (lines) concentrations of (A) Tri and (B) TriO in the CFSTR under various $[\mathrm{OH}]$.

A model sensitivity test is performed and shown in Fig. S12. The base model, shown in Table S1, uses SAR to compute $\mathrm{OH}$ addition and $\mathrm{H}$-abstraction rate coefficients. These computed rate coefficients are changed by a factor of 5 and compared to the experimentally observed Tri decay at $[\mathrm{OH}]=1.6 \times 10^{7}$ molecules $\mathrm{cm}^{-3}$. The decay of Tri becomes faster (or slower) by increasing the rate constant of $\mathrm{OH}$ addition (or $\mathrm{H}$-abstraction), respectively. This is mainly because of the $\mathrm{OH}$ addition regenerates the $\mathrm{CI}$ via $\mathrm{R} 13$, which further propagates radical chain oxidation. 


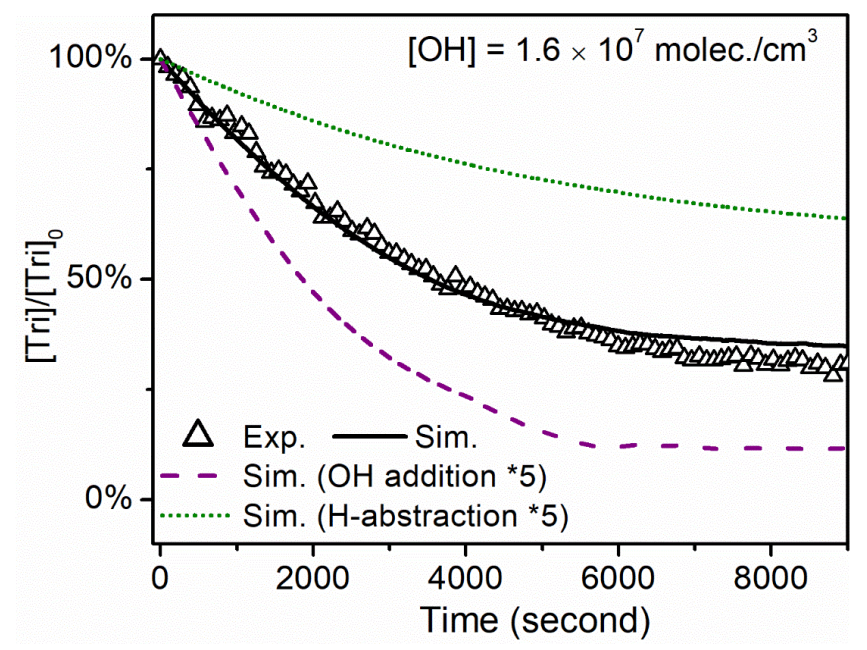

Figure S12. Sensitivity test of $\mathrm{H}$-abstraction and $\mathrm{OH}$ addition rate coefficients. Symbols and lines are experimental and simulated results, respectively.

\section{S2.4. Simulation results for $\mathrm{Tri}+\mathrm{O}_{3}$ reactions in the flow reactor}

The kinetic model is compared with the Tri $+\mathrm{O}_{3}$ experiments in the flow reactor. Figure S13 shows the simulated and experimental kinetics of Tri and TriO as a function of $\mathrm{O}_{3}$ exposure (i.e. $\left[\mathrm{O}_{3}\right] \times$ time). The model predictions are in reasonable agreement with experiments.

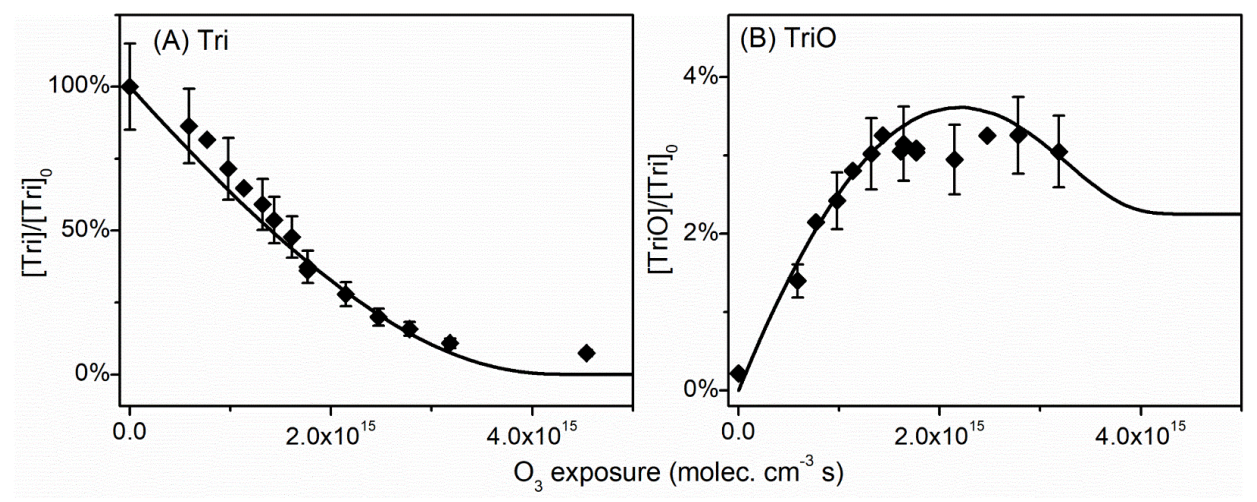

Figure S13. Experimental (symbols) and simulated (lines) normalized concentrations of Tri and TriO during Tri $+\mathrm{O}_{3}$ reactions in the flow reactor (the average $\left[\mathrm{O}_{3}\right] \sim 4.0 \times 10^{13}$ molecules $\cdot \mathrm{cm}^{-3}$ ). 
A similar test, as was presented above for the Tri $+\mathrm{OH}$ reactions in Fig. S12, was conducted to examine the model sensitivity to the rate constants for $\mathrm{OH}$ addition and $\mathrm{H}$-abstraction. As shown in Fig. S14, the decay of Tri becomes slower by increasing the rate constant for H-abstraction reaction. This is consistent with $\mathrm{H}$-abstraction pathways leading to chain terminating products, whereas $\mathrm{OH}$ addition propagates further oxidation through the CI. Overall, the sensitivity tests show in Figs. S12 and S14 suggest that the SAR values in the model provide a reasonable description of the free radical sub-mechanism.

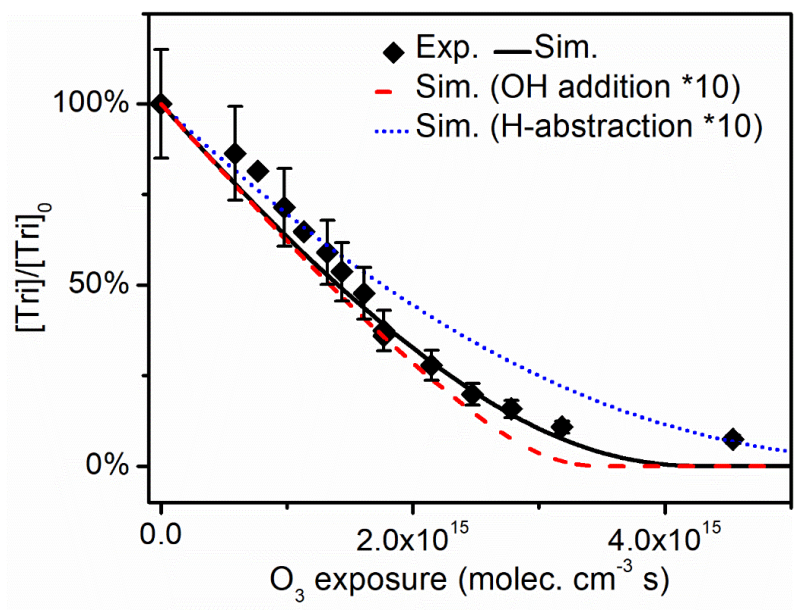

Figure S14. Sensitivity test of $\mathrm{H}$-abstraction and $\mathrm{OH}$ addition rate coefficients. Symbols and lines are experimental and simulated results, respectively. 


\section{REFERENCES}

(1) Che, D. L.; Smith, J. D.; Leone, S. R.; Ahmed, M.; Wilson, K. R. Quantifying the reactive uptake of $\mathrm{OH}$ by organic aerosols in a continuous flow stirred tank reactor. Phys. Chem. Chem. Phys. 2009, 11, 7885-7895.

(2) Zeng, M.; Heine, N.; Wilson, K. R. Evidence that Criegee intermediates drive autoxidation in unsaturated lipids. Proc. Natl. Acad. Sci. U.S.A. 2020, 117, 4486-4490.

(3) Heine, N.; Houle, F. A.; Wilson, K. R. Connecting the elementary reaction pathways of Criegee intermediates to the chemical erosion of squalene interfaces during ozonolysis. Environ. Sci. Technol. 2017, 51, 13740-13748.

(4) Smith, J. D.; Kroll, J. H.; Cappa, C. D.; Che, D. L.; Liu, C. L.; Ahmed, M.; Leone, S. R.; Worsnop, D. R.; Wilson, K. R. The heterogeneous reaction of hydroxyl radicals with sub-micron squalane particles: a model system for understanding the oxidative aging of ambient aerosols. Atmos. Chem. Phys. Discuss. 2009, 9, 3945-3981.

(5) Wilson, K. R.; Jimenez-Cruz, M.; Nicolas, C.; Belau, L.; Leone, S. R.; Ahmed, M. Thermal vaporization of biological nanoparticles: fragment-free vacuum ultraviolet photoionization mass spectra of tryptophan, phenylalanine-glycine-glycine, and $\beta$-carotene. J. Phys. Chem. A 2006, 110, 2106-2113.

(6) Liu, C. L.; Smith, J. D.; Che, D. L.; Ahmed, M.; Leone, S. R.; Wilson, K. R. The direct observation of secondary radical chain chemistry in the heterogeneous reaction of chlorine atoms with submicron squalane droplets. Phys. Chem. Chem. Phys. 2011, 13, 8993-9007.

(7) Hasson, A. S.; Chung, M. Y.; Kuwata, K. T.; Converse, A. D.; Krohn, D.; Paulson, S. E. Reaction of Criegee intermediates with water vapors - an additional source of $\mathrm{OH}$ radicals in alkene ozonolysis? J. Phys. Chem. A 2003, 107, 6176-6182.

(8) Kumar, M.; Busch, D. H.; Subramaniam, B.; Thompson, W. H. Role of tunable acid catalysis in decomposition of $\alpha$-hydroxyalkyl hydroperoxides and mechanistic implications for tropospheric chemistry. J. Phys. Chem. A 2014, 118, 9701-9711.

(9) Hinsberg, W.; Houle, F., Kinetiscope: a stochastic kinetics simulator, Version 1.1.956, 2020, http://hinsberg.net/kinetiscope/.

(10) Houle, F. A.; Hinsberg, W. D.; Wilson, K. R. Oxidation of a model alkane aerosol by OH radical: the emergent nature of reactive uptake. Phys. Chem. Chem. Phys. 2015, 17, 4412-4423.

(11) Houle, F. A.; Wiegel, A. A.; Wilson, K. R. Changes in reactivity as chemistry becomes confined to an interface. The case of free radical oxidation of $\mathrm{C}_{30} \mathrm{H}_{62}$ alkane by OH. J. Phys. Chem. Lett. 2018, 9, 1053-1057.

(12) Houle, F. A.; Wiegel, A. A.; Wilson, K. R. Predicting aerosol reactivity across scales: from the laboratory to the atmosphere. Environ. Sci. Technol. 2018, 52, 13774-13781.

(13) Wiegel, A. A.; Wilson, K. R.; Hinsberg, W. D.; Houle, F. A. Stochastic methods for aerosol chemistry: a compact molecular description of functionalization and fragmentation in the heterogeneous oxidation of squalane aerosol by OH radicals. Phys. Chem. Chem. Phys. 2015, 17, 4398-4411.

(14) Heine, N.; Arata, C.; Goldstein, A. H.; Houle, F. A.; Wilson, K. R. Multiphase mechanism for the production of sulfuric acid from $\mathrm{SO}_{2}$ by Criegee intermediates formed during the heterogeneous reaction of ozone with squalene. J. Phys. Chem. Lett. 2018, 9, 3504-3510.

(15) Richards-Henderson, N. K.; Goldstein, A. H.; Wilson, K. R. Large enhancement in the heterogeneous oxidation rate of organic aerosols by hydroxyl radicals in the presence of nitric oxide. J. Phys. Chem. Lett. 2015, 6, 4451-4455. 
(16) Richards-Henderson, N. K.; Goldstein, A. H.; Wilson, K. R. Sulfur dioxide accelerates the heterogeneous oxidation rate of organic aerosol by hydroxyl radicals. Environ. Sci. Technol. 2016, 50, 3554-3561.

(17) Li, M.; Su, H.; Li, G.; Ma, N.; Pöschl, U.; Cheng, Y. Relative importance of gas uptake on aerosol and ground surfaces characterized by equivalent uptake coefficients. Atmos. Chem. Phys. 2019, 19, 10981-11011.

(18) Stephens, S.; Rossi, M. J.; Golden, D. M. The Heterogeneous Reaction of Ozone on Carbonaceous Surfaces. Int. J. Chem. Kinet. 1986, 18, 1133-1149.

(19) Zhou, S.; Forbes, M. W.; Abbatt, J. P. Kinetics and products from heterogeneous oxidation of squalene with ozone. Environ. Sci. Technol. 2016, 50, 11688-11697.

(20) Zhou, Z.; Zhou, S.; Abbatt, J. P. D. Kinetics and condensed-phase products in multiphase ozonolysis of an unsaturated triglyceride. Environ. Sci. Technol. 2019, 53, 12467-12475.

(21) Zhang, X.; Barraza, K. M.; Beauchamp, J. L. Cholesterol provides nonsacrificial protection of membrane lipids from chemical damage at air-water interface. Proc. Natl. Acad. Sci. U.S.A. 2018, 27, 3255-3260.

(22) Zhang, X.; Barraza, K. M.; Upton, K. T.; Beauchamp, J. L. Subtle changes in lipid environment have profound effects on membrane oxidation chemistry. J. Am. Chem. Soc. 2018, $140,17492-17498$.

(23) Vereecken, L.; Novelli, A.; Taraborrelli, D. Unimolecular decay strongly limits the atmospheric impact of Criegee intermediates. Phys. Chem. Chem. Phys. 2017, 19, 31599-31612.

(24) Peeters, J.; Boullart, W.; Pultau, V.; Vandenberk, S.; Vereecken, L. Structure-activity relationship for the addition of $\mathrm{OH}$ to (poly)alkenes: site-specific and total rate constants. J. Phys. Chem. A 2007, 111, 1618-1631.

(25) Denisov, E. T.; Afanas'ev, I. B., Oxidation and Antioxidants in Organic Chemistry and Biology. Taylor \& Frances: Oxford, 2005.

(26) Vereecken, L.; Peeters, J. H-atom abstraction by OH-radicals from (biogenic) (poly)alkenes: $\mathrm{C} \pm \mathrm{H}$ bond strengths and abstraction rates. Chem. Phys. Lett. 2001, 333, 162-168.

(27) Atkinson, R. Estimations of $\mathrm{OH}$ radical rate constants from $\mathrm{H}$-atom abstraction from $\mathrm{C}-\mathrm{H}$ and O-H bonds over the temperature range 250-1000 K. Int. J Chem. Kinet. 1986, 18, 555-568.

(28) Buras, Z. J.; Elsamra, R. M.; Jalan, A.; Middaugh, J. E.; Green, W. H. Direct kinetic measurements of reactions between the simplest Criegee intermediate $\mathrm{CH}_{2} \mathrm{OO}$ and alkenes. $J$. Phys. Chem. A 2014, 118, 1997-2006.

(29) Tsang, W. Chemical Kinetic Data Base for Combustion Chemistry Part V. Propene. J. Phys. Chem. Ref. Data 1991, 20, 221-273.

(30) Villano, S. M.; Huynh, L. K.; Carstensen, H. H.; Dean, A. M. High-pressure rate rules for alkyl $+\mathrm{O}_{2}$ reactions. 1. The dissociation, concerted elimination, and isomerization channels of the alkyl peroxy radical. J. Phys. Chem. A 2011, 115, 13425-13442.

(31) Zádor, J.; Miller, J. A. Adventures on the $\mathrm{C}_{3} \mathrm{H}_{5} \mathrm{O}$ potential energy surface: $\mathrm{OH}+$ propyne, $\mathrm{OH}$ + allene and related reactions. Proc. Combust. Inst. 2015, 35, 181-188.

(32) Curran, H. J. Rate constant estimation for $\mathrm{C}_{1}$ to $\mathrm{C}_{4}$ alkyl and alkoxyl radical decomposition. Int. J. Chem. Kinet. 2006, 38, 250-275.

(33) Vereecken, L.; Harder, H.; Novelli, A. The reactions of Criegee intermediates with alkenes, ozone, and carbonyl oxides. Phys. Chem. Chem. Phys. 2014, 16, 4039-4049.

(34) Petrick, L.; Dubowski, Y. Heterogeneous oxidation of squalene film by ozone under various indoor conditions. Indoor Air 2009, 19, 381-391. 
(35) Wells, J. R.; Morrison, G. C.; Coleman, B. K. Kinetics and Reaction Products of Ozone and Surface-Bound Squalene. J. ASTM Int. 2008, 5, 1-12.

(36) Zhou, S.; Joudan, S.; Forbes, M. W.; Zhou, Z.; Abbatt, J. P. D. Reaction of condensed-phase Criegee intermediates with carboxylic acids and perfluoroalkyl carboxylic acids. Environ. Sci. Technol. Lett. 2019, 6, 243-250.

(37) Carstensen, H.-H.; Dean, A. M. Rate constants for the abstraction reactions $\mathrm{RO}_{2}+\mathrm{C}_{2} \mathrm{H}_{6} ; \mathrm{R}=$ $\mathrm{H}, \mathrm{CH}_{3}$, and $\mathrm{C}_{2} \mathrm{H}_{5}$. Proc. Combust. Inst. 2005, 30, 995-1003.

(38) Carstensen, H.-H.; Dean, A. M.; Deutschmann, O. Rate constants for the H abstraction from alkanes $(\mathrm{R}-\mathrm{H})$ by $\mathrm{R}^{\prime} \mathrm{O}_{2}$ radicals: A systematic study on the impact of $\mathrm{R}$ and $\mathrm{R}$ '. Proc. Combust. Inst. 2007, 31, 149-157.

(39) Zádor, J.; Taatjes, C. A.; Fernandes, R. X. Kinetics of elementary reactions in lowtemperature autoignition chemistry. Prog. Energy Combust. Sci. 2011, 37, 371-421. 